\title{
Telomere length homeostasis
}

\author{
Nele Hug • Joachim Lingner
}

Received: 24 February 2006 /Revised: 5 April 2006 / Accepted: 6 April 2006 / Published online: 2 June 2006

(C) Springer-Verlag 2006

\begin{abstract}
The physical ends of chromosomes, known as telomeres, protect chromosome ends from nucleolytic degradation and DNA repair activities. Conventional DNA replication enzymes lack the ability to fully replicate telomere ends. In addition, nucleolytic activities contribute to telomere erosion. Short telomeres trigger DNA damage checkpoints, which mediate cellular senescence. Telomere length homeostasis requires telomerase, a cellular reverse transcriptase, which uses an internal RNA moiety as a template for the synthesis of telomere repeats. Telomerase elongates the 3 ' ends of chromosomes, whereas the complementary strand is filled in by conventional DNA polymerases. In humans, telomerase is ubiquitously expressed only during the first weeks of embryogenesis, and is subsequently downregulated in most cell types. Correct telomere length setting is crucial for long-term survival. The telomere length reserve must be sufficient to avoid premature cellular senescence and the acceleration of age-related disease. On the other side, telomere shortening suppresses tumor formation through limiting the replicative potential of cells. In recent years, novel insight into the regulation of telomerase at chromosome ends has increased our understanding on how telomere length homeostasis in telomerasepositive cells is achieved. Factors that recruit telomerase to telomeres in a cell cycle-dependent manner have been identified in Saccharomyces cerevisiae. In humans, telo-
\end{abstract}

Communicated by E.A. Nigg

N. Hug $\cdot$ J. Lingner $(\bowtie)$

Swiss Institute for Experimental Cancer Research (ISREC)

and National Center of Competence in Research

"Frontiers in Genetics",

École Polytechnique Fédérale de Lausanne (EPFL),

Chemin des Boveresses 155,

CH-1066 Epalinges s/Lausanne, Switzerland

e-mail: joachim.lingner@isrec.ch merase assembles with telomeres during $\mathrm{S}$ phase of the cell cycle. Presumably through mediating formation of alternative telomere structures, telomere-binding proteins regulate telomerase activity in cis to favor preferential elongation of the shortest telomeres. Phosphoinositide 3-kinase related kinases are also required for telomerase activation at chromosome ends, at least in budding and fission yeast. In vivo analysis of telomere elongation kinetics shows that telomerase does not act on every telomere in each cell cycle but that it exhibits an increasing preference for telomeres as their lengths decline. This suggests a model in which telomeres switch between extendible and nonextendible states in a length-dependent manner. In this review we expand this model to incorporate the finding that telomerase levels also limit telomere length and we propose a second switch between a non-telomerase-associated "extendible" and a telomerase-associated "extending" state.

\section{Introduction}

All eukaryotes, and a few prokaryotes, keep their genomes in the form of linear DNA molecules. This requires special mechanisms to fully replicate DNA ends because of the following reasons: First, DNA replication is semiconservative; DNA polymerases use a parental template strand to synthesize a complementary daughter molecule. Eukaryotic telomeres end with $3^{\prime}$ protrusions at both chromosomal ends, as demonstrated for ciliated protozoa, budding yeast, and human telomeres (Klobutcher et al. 1981; Makarov et al. 1997; Chai et al. 2006a; Wellinger et al. 1993). Thus, the $5^{\prime}$ parental strand is resected and it cannot provide a template for the synthesis of a $3^{\prime}$ overhang [Fig. 1b,c, leading strand (Lingner et al. 1995)]. Semiconservative replication of the 5'-end-containing strand during leading 


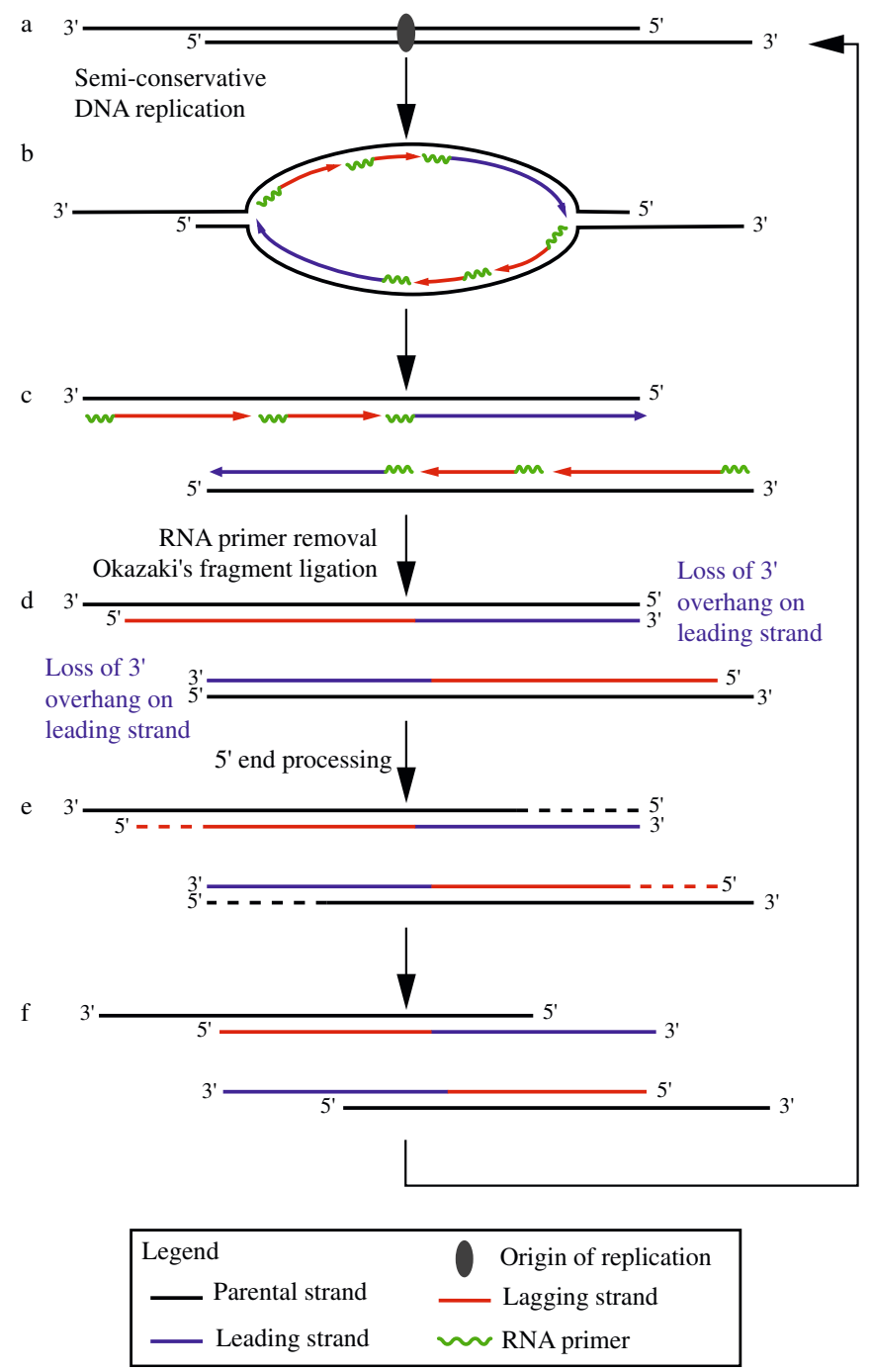

Fig. 1 The DNA end replication problem. DNA replication starts at replication origins (a, gray oval). For simplicity, only one origin of replication is shown. The replication forks move in opposite directions (b). Because DNA polymerases only elongate in the $5^{\prime}$ to $3^{\prime}$ direction, each fork contains a leading (continuous) and a lagging (discontinuous) strand. Lagging strand synthesis is primed by short RNA

strand synthesis should lead to loss of the $3^{\prime}$ overhang. However, the presumed blunt end intermediate is not detected and the templating strand is probably quickly resected to regenerate the $3^{\prime}$ overhang. Therefore, nucleolytic processing of telomere ends after semiconservative DNA replication contributes to telomere shortening [Fig. 1e,f (Chai et al. 2006b; Jacob et al. 2003; Larrivee et al. 2004)]. Chromosome end processing may occur also at the lagging strand telomere (Sfeir et al. 2005). Second, DNA polymerases cannot start DNA synthesis de novo. Instead, DNA polymerases extend short RNA primers, 8 12 nucleotides in length, which are synthesized by primases. Removal of RNA primers will leave a gap behind and therefore, DNA polymerases cannot synthesize oligonucleotides (wavy line). Terminal DNA is lost at the leading strand end because the parental 5'-end-containing template is recessed (d). If RNA primers were laid down on the $3^{\prime}$ overhang as depicted in (c), their removal would not lead to a net loss of sequence at the lagging strand. Finally, $5^{\prime}$-end processing occurs to regenerate a $3^{\prime}$ overhang at the leading strand telomere $(\mathbf{e}, \mathbf{f})$

the extreme $5^{\prime}$ end of a blunt end DNA molecule. Thus, upon replication of the $3^{\prime}$-end-containing strand during lagging strand synthesis, one would predict sequence loss that corresponds at least to the length of the RNA primer (Olovnikoff 1973; Watson 1972). However, because the parental DNA strand is protruding at this end, the loss of DNA during semiconservative DNA replication depends on where the most distal RNA primer is laid down with respect to the overhang. If laid down on the $3^{\prime}$ overhang only, no sequence will be lost upon primer removal (Fig. 1c,d, lagging strand).

The most common way out of the end replication problem occurs through the ribonucleoprotein (RNP) enzyme telomerase, discovered in 1985 in the holotrichous 


\section{A Saccharomyces cervisiae telomerase}

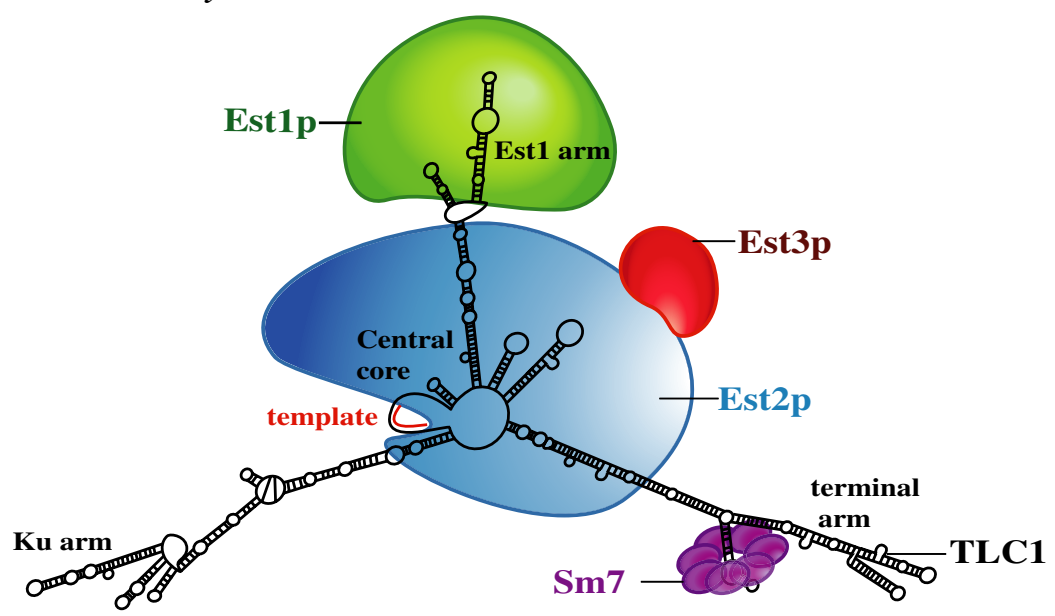

B Homo sapiens telomerase

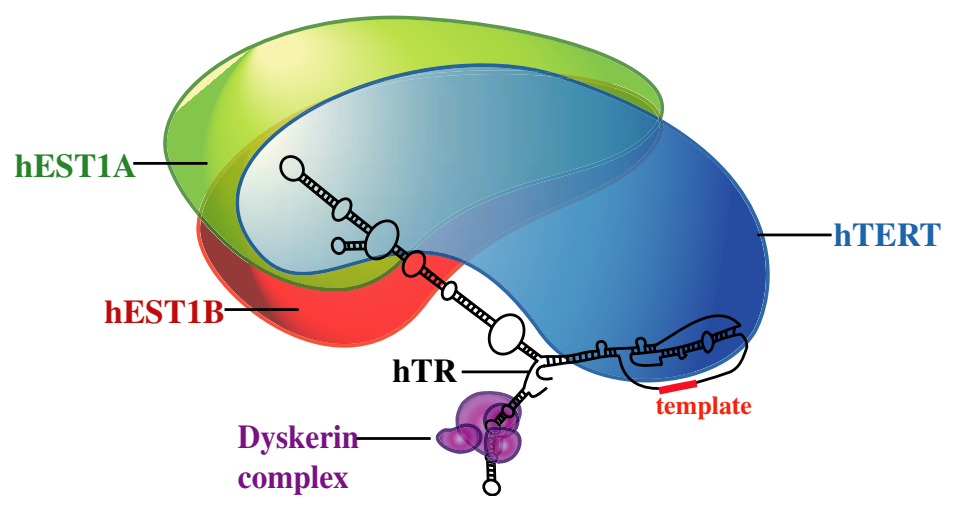

Fig. 2 Telomerase models. a Saccharomyces cerevisiae telomerase. The telomerase RNA secondary structure is based on published models (Dandjinou et al. 2004; Zappulla and Cech 2004). The protein subunits are discussed in the text. b Homo sapiens telomerase. The telomerase RNA secondary structure is based on the published model (Chen et al. 2000). The protein subunits are discussed in the text. A large set of additional proteins, which are not represented, has been reported to interact with human telomerase ciliate Tetrahymena thermophila by Carol Greider and Elizabeth Blackburn (Greider and Blackburn 1985). The telomerase enzyme contains an RNA moiety (Greider and Blackburn 1987) with a sequence complementary to the telomeric repeats (Greider and Blackburn 1989), which serves as a template for reverse transcription ( $\mathrm{Yu}$ et al. 1990) (Fig. 2). The telomerase reverse transcriptase (TERT; Est2p in Saccharomyces cerevisiae) catalyzes reverse transcription of the RNA template into telomeric repeats (Lingner et al. 1997) while the telomerase subunit Estlp and the telomerase interacting protein $\mathrm{Ku}$ in $S$. cerevisiae are required for telomerase recruitment [(Lendvay et al. 1996; Lundblad and Szostak 1989; Stellwagen et al. 2003) discussed below]. Telomerase-associated proteins involved in biogenesis are shared with other small nuclear (sn) or nucleolar (sno) RNPs and their identity is not conserved in different phyla (Fig. 2). The dyskerin complex, which is part of vertebrate telomerases and of snoRNPs is involved in RNP biogenesis and stability (Mitchell et al. 1999). Sm proteins, which associate also with snRNPs, form part of yeast telomerases (Seto et al. 1999; for reviews on telomerase and its biogenesis, see Chen and Greider 2006; Cristofari and Lingner 2006a). Telomerase activity at chromosome ends is regulated by telomere-binding proteins and phosphoinositide 3-kinase related kinases (PIKKs), and its action is coordinated with semiconservative DNA replication in a cell cycle-dependent manner.

In this review, we first describe the roles of telomere proteins to specify different telomeric states, which in turn regulate the telomerase enzyme. Then, we describe how 
A Saccharomyces cervisiae

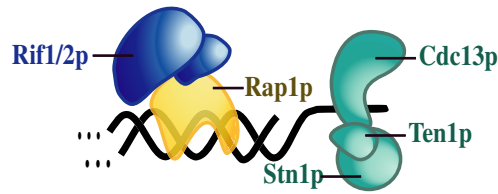

B Homo sapiens

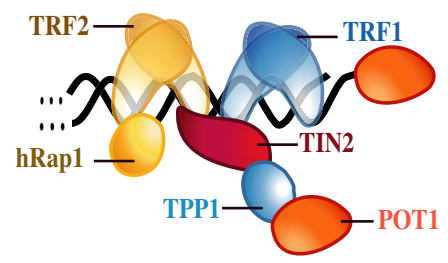

C Telomere structure models
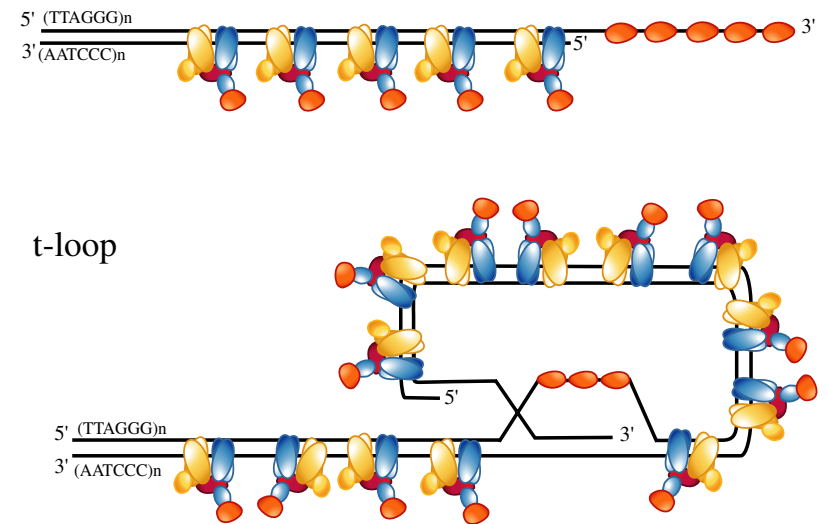

Fig. 3 Telomere proteins and structures. Only a subset of the proteins is depicted

telomerase activity assembles with chromosome ends in a cell cycle-dependent manner. Finally, we integrate the current knowledge of telomerase regulation into an expanded model for telomere length homeostasis. Through most parts of this review, we focus on knowledge gained in the yeast $S$. cerevisiae and in human cells.

\section{Telomeric states}

Telomeric DNA in most eukaryotes consists of short tandem repeats, which are G-rich in the strand containing the $3^{\prime}$ end. This strand is referred to the G-strand, whereas the $5^{\prime}$-end-containing complementary strand is referred to as $\mathrm{C}$-strand. In humans the telomeric repeat sequence is $5^{\prime}$ TTAGGG-3', while in budding yeast telomeric DNA contains degenerate repeat sequences with the consensus 5'-(TG) $)_{0-6}$ TGGGTGTG(G)-3'. In cells that express telomerase, telomere length is kept within a species- and cell type-specific narrow range. The length of the duplex telomeric tract ranges from $<30 \mathrm{bp}$ in some ciliates, to
200-300 bp in budding yeast, to $5-15 \mathrm{~kb}$ in humans, and up to $\sim 50 \mathrm{~kb}$ in mice. The telomeric $3^{\prime}$ overhang has a length of a few nucleotides in ciliates and roughly $30-110$ nucleotides in humans (Chai et al. 2006a; Klobutcher et al. 1981). Yeast telomeres exhibit short 3 ' overhangs of 12-14 nucleotides throughout most of the cell cycle (Larrivee et al. 2004). Only in S phase, upon replication by the conventional DNA machinery, can longer overhangs be detected (Wellinger et al. 1993). The generation of the short overhangs outside of S phase depends on Mre $11 \mathrm{p}$, which is part of the Mre11-Rad50-Xrs2 complex (MRX). The overhangs during $\mathrm{S}$ phase are also reduced in mrell $\Delta$ strains (Larrivee et al. 2004). In human cells, downregulation of the Mre11-Rad50-Nbs1 complex (MRN) resulted in transient shortening of the $3^{\prime}$ overhangs in telomerase-positive but not in telomerase-negative cells (Chai et al. 2006b). This has been interpreted to suggest that MRN is involved in telomerase recruitment (Chai et al. 2006b). To conclude, although the MRN/MRX complexes seem to contribute to nucleolytic processing of chromosome ends, the identity of the nucleases that generate, 
during $\mathrm{S}$ phase, upon semiconservative DNA replication, the $3^{\prime}$ overhang at leading strand telomeres remains elusive.

The telomeric repeat sequences are associated with a group of specialized telomere-binding proteins to protect chromosome ends from degradation and from end-to-end joining events (Fig. 3). At the same time, telomere-binding proteins regulate telomerase activity to achieve telomere length homeostasis. Although telomere function is conserved to a large extent across species, the telomere protein organization varies significantly, as discussed in the next section.

\section{Double-strand telomere-binding proteins}

Budding yeast Raplp is a major component of telomeric chromatin that binds the telomeric repeats with high affinity through a Myb-like DNA binding domain. Raplp negatively affects telomere length (Conrad et al. 1990; Lustig et al. 1990). It recruits, through a C-terminal domain, two proteins, Riflp and Rif2p, which mediate the telomere length control (Hardy et al. 1992; Wotton and Shore 1997) (Fig. 3). Deletion of either RIF1 or RIF2 leads to substantial elongation of telomeres establishing their function as negative regulators of telomere length. Telomere elongation analysis of single-chromosome end molecules in rifl and rif2-mutant cells reveals that these proteins downregulate the frequency of telomerase-mediated telomere elongation (Teixeira et al. 2004; discussed below). However, the exact mechanism by which Rifl and Rif2 transmit their signal to telomerase remains unclear. Subtelomeric chromatin also contributes to telomere length control (Berthiau et al. 2006).

In humans, six proteins, TRF1, TRF2, hRap1, TIN2, TPP1, and POT1, form the so-called shelterin complex, which is a constitutive component of human telomeres (reviewed by de Lange 2005). The related TRF1 and TRF2 proteins bind double-stranded telomeric repeats as preformed homodimers (Bianchi et al. 1997), whereas POT1 binds to the single-stranded telomeric 3' overhang (Fig. 3). TIN2 connects, through protein interactions, TRF1, TRF2, and TPP1. TPP1 binds, in addition, POT1, thus recruiting POT1 also to the double-stranded part of telomeres. Human Rap1, the ortholog of yeast Rap1, associates with telomeres through interaction with TRF2. POT1 has also been reported to interact directly with TRF2 (Houghtaling et al. 2004; Kim et al. 1999; Li et al. 2000; Liu et al. 2004a,b; Loayza and De Lange 2003; O'Connor et al. 2004; Yang et al. 2005; Ye et al. 2004a,b).

Shelterin is involved in telomere length control. Disturbing expression levels of shelterin components strongly impacts on telomere length (reviewed by Smogorzewska and De Lange 2004). For example, inhibition of TRF1 leads to telomere elongation in human tumor cells, while overexpression of TRF1 causes telomere shortening without affecting telomerase activity in vitro (van Steensel and de Lange 1997). The binding of TRF1 to telomeres is controlled by tankyrase 1 and 2, poly[adenosine diphosphate (ADP)-ribose] polymerases, which modify TRF1 by the addition of ADP-ribosylation polymers, thus inhibiting the capability of TRF1 to bind telomeric DNA in vitro and in vivo (Cook et al. 2002; Kaminker et al. 2001; Sbodio et al. 2002; Seimiya and Smith 2002; Smith and de Lange 2000; Smith et al. 1998). Upon telomere dissociation, TRF1 is degraded by ubiquitin-mediated proteolysis (Chang et al. 2003). TIN2 protects TRF1 from tankyrase modification (Ye et al. 2004b). Reduction of TIN2 protein levels or the overexpression of mutant alleles that disrupt TIN2 interaction with TRF1 and TRF2 leads to telomere lengthening (Kim et al. 2004; Ye and de Lange 2004). Suppression of TPP1 by RNAi or the disruption of the TPP1-POT1 interaction also results in telomere lengthening, accompanied by loss of the POT1 signal at telomeres (Liu et al. 2004b; Ye et al. 2004b). Overexpression of TRF2 causes telomere shortening (Smogorzewska et al. 2000), but this shortening does not only occur through in vivo inhibition of telomerase, but also through an increased shortening rate (Ancelin et al. 2002). Finally, perturbation of Rap1 expression levels leads to mild telomere lengthening ( $\mathrm{Li}$ and de Lange 2003; O'Connor et al. 2004).

How does shelterin mediate telomerase control at the $3^{\prime}$ end of the telomere? Longer telomeres load more shelterin complexes and this may provide a length-sensing mechanism (Smogorzewska et al. 2000). As discussed below, the association of POT1 with shelterin may affect POT1 loading on the single-stranded telomeric DNA where it may act as an inhibitor of telomerase activity (Loayza and de Lange 2003). Alternatively or in addition, shelterin may inhibit telomerase by promoting the formation of the t-loop structure, in which the $3^{\prime}$ overhang is inaccessible, being tucked into the double-stranded part of the telomere (Griffith et al. 1999) (Fig. 3c). In addition to shelterin, telomere length is also negatively regulated by histone methyltransferases in the mouse, which may be required to assemble telomeric heterochromatin (Garcia-Cao et al. 2004).

\section{Single-strand telomere-binding proteins}

Single-strand telomere-binding proteins regulate telomerase access to the telomeric $3^{\prime}$ end. In $S$. cerevisiae, Cdc13p is the major single-strand DNA-binding protein. Cdc13p's functions include telomerase recruitment, telomerase repression, coordination of G- and C-strand synthesis, and protection of telomere ends from nucleolytic degradation. The latter task is immediately essential for viability. Loss of CDC13 leads to degradation of the telomeric C-rich strand, 


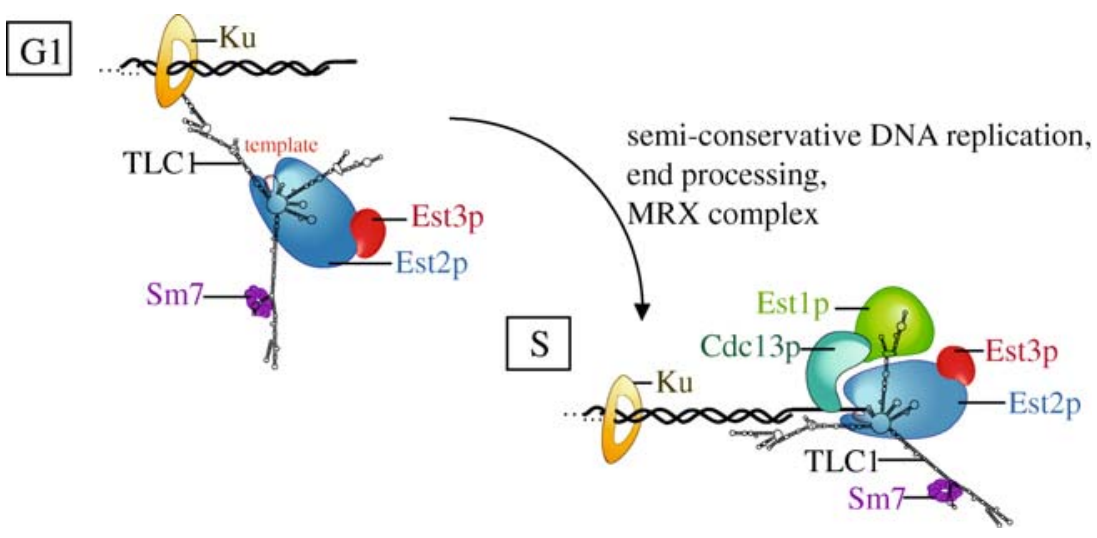

Fig. 4 Recruitment pathways for S. cerevisiae telomerase. The Ku70/ 80-hetero-dimer recruits telomerase in $\mathrm{G} 1$ through binding the $\mathrm{Ku}$ stem loop in the TLC1 telomerase RNA. This recruitment pathway

causing a Rad9-mediated cell-cycle arrest (Garvik et al. 1995). Cdc13p is present at telomeres throughout the cell cycle (Bourns et al. 1998; Schramke et al. 2004; Taggart et al. 2002), but the levels of Cdc13p at telomeres peak in late $\mathrm{S}$ phase, consistent with the idea that $\mathrm{Cdc13p}$ assembles along the extended telomeric $3^{\prime}$ overhang present at that time. The $c d c 13-2$ and $c d c 13-5$ mutant alleles uncovered two separate functions for $\mathrm{Cdc} 13 \mathrm{p}$ in telomere replication (Chandra et al. 2001; Nugent et al. 1996). The cdc13-2 allele shows an in vivo telomerase defect, which results from a disturbed interaction with the Estlp subunit of telomerase (Bianchi et al. 2004; Evans and Lundblad 1999; Lendvay et al. 1996; Nugent et al. 1996; Pennock et al. 2001; discussed further below). The $c d c 13-5$ allele gives rise to overelongated telomeres and overly long $3^{\prime}$ overhangs, pointing to a defect in $\mathrm{C}$-strand synthesis by the lagging strand DNA replication machinery (Chandra et al. 2001). Indeed, Cdc13p limits telomerase-mediated telomere elongation in conjunction with $\operatorname{Stn} 1 \mathrm{p}$ and Ten $1 \mathrm{p}$, two essential Cdc13-associated proteins (Grandin et al. 1997, 2001.

The presumed major single-stranded telomere-binding protein in humans, POT1 (Baumann and Cech 2001), has been proposed to act as the terminal transducer of telomere length control from TRF1 (Loayza and De Lange 2003). POT1 binds single-stranded telomeric DNA with high sequence-specificity using two oligonucleotide/oligosaccharide-binding (OB) folds (Lei et al. 2004). Overexpression of a mutant POT1 allele that lacks the first OB fold resulted in rapid telomere elongation (Loayza and de Lange 2003). Similarly, siRNA-mediated depletion of hPOT1 resulted in telomere elongation (Ye et al. 2004b). In other studies, however, expression of the full-length protein caused telomere elongation (Armbruster et al. 2004; Colgin et al. 2003). The crystal structure of the N-terminal half of human POT1 containing the two OB folds with telomeric does not enable telomerase-mediated telomere elongation, but increases the elongation's efficiency. In S phase, Cdc13p recruits telomerase through binding telomerase-associated Est1p

DNA oligonucleotides shows that the $3^{\prime}$ terminal $G$ is buried in the protein, which should render it inaccessible to telomerase (Lei et al. 2004). Indeed, association of recombinant POT1 with telomeric oligonucleotide ends inhibits binding of telomerase (Kelleher et al. 2005; Lei et al. 2005). On the other hand, POT1 is able to disrupt Gquadruduplex structures, which form through Hoogsteen base pairing in telomeric DNA in vitro. This could also explain how POT1 positively contributes to telomerasedependent elongation, because G-quadruduplex structures represent very poor substrates for telomerase (Zahler et al. 1991; Zaug et al. 2005). The disruption of G-quadruplex structures could also be facilitated by the recruitment of WRN or BLM helicases, both of which were shown to physically interact with POT1 (Opresko et al. 2005).

\section{Regulation of the telomerase enzyme in a cell cycle-dependent manner}

In $S$. cerevisiae, telomere elongation of an artificially shortened telomere coincides with semiconservative telomere replication, which occurs late in S phase, suggesting coupling between the two processes. No elongation occurs in G1 of the cell cycle or in nocodazole-arrested cells (Marcand et al. 2000). The latter finding contrasts telomere addition to a double-stranded DNA break adjacent to a short telomeric DNA tract, which can occur in nocodazolearrested cells in M phase (Diede and Gottschling 1999). Genetic evidence further supports the coupling of telomerase action with semiconservative DNA replication. Telomere addition to the double strand breaks in nocodazolearrested cells depends on functional DNA polymerases $\alpha$ and $\delta$ (Diede and Gottschling 1999). Mutations in DNA polymerase $\alpha$ cause telomere lengthening in $S$. cerevisiae and in mouse cells (Adams and Holm 1996; Nakamura et 
al. 2005). The B subunit of DNA polymerase $\alpha$ physically and genetically interacts with the Cdc13p-interacting protein Stn1 (Grossi et al. 2004). In addition, Cdc13p interacts with the catalytic subunit of DNA polymerase $\alpha$ (Qi and Zakian 2000). Thus, the end protein complex not only regulates telomerase recruitment and activity but may also orchestrate telomerase action with lagging strand DNA synthesis.

Telomerase assembles with telomeres in $S$. cerevisiae and in humans in a cell cycle-dependent manner. In $S$. cerevisiae, two separate pathways of telomerase recruitment appear to exist (Fig. 4). Cdc13p binds the telomeraseassociated Estlp, and this interaction is essential for telomerase activity at chromosome ends (Pennock et al. 2001). The recruitment function of $\mathrm{Cdc} 13$ is reduced by a point mutation ( $c d c 13-2)$ at amino acid 252 (Glu $\rightarrow$ Lys), which can be suppressed by a missense mutation at residue 444 of Est1p (Lys $\rightarrow$ Glu). This reciprocal suppression depends on oppositely charged residues in Cdc13 and Est1, providing excellent evidence for a direct physical interaction between these two proteins (Pennock et al. 2001). Studies with fusion proteins are consistent with a model in which the interaction between Est1p and Cdc13p mediates the recruitment of telomerase (Evans and Lundblad 1999). Strikingly, a fusion between Cdc13p and Est2p allows telomere maintenance even in the absence of Estlp. Recruitment assays to DNA breaks containing telomere repeat sequences at the break site further support the telomerase recruitment functions of Cdc13 and Est1 (Bianchi et al. 2004). Chromatin immunoprecipitation (ChIP) experiments demonstrate preferential association of Est1p with telomeres during $\mathrm{S}$ phase, thus correlating well with the time of telomerase action (Schramke et al. 2004; Taggart et al. 2002).

In budding yeast, the MRX complex and the ATM and ATR-related PIKKs, Tell and Mec1, have also been implicated in the hierarchical assembly of telomerase at the $3^{\prime}$ end during $\mathrm{S}$ phase. Simultaneous deletion of these two PIKKs in fission or budding yeast gives an EST phenotype (Naito et al. 1998; Ritchie et al. 1999). Mec1 is recruited to telomeres during late $\mathrm{S}$ phase, whereas Tel1 associates with telomeres in G1 (Takata et al. 2004). MRX, which binds to telomeres also in late $\mathrm{S}$ phase, is required for the efficient recruitment of Mec1, Cdc13p, and Est1 at the telomere (Takata et al. 2005). However, because mutations in MRX or MEC1 per se do not trigger an EST phenotype, Cdc13p- and Est1p-recruitment must still occur even in the absence of these factors. As mentioned above, the MRN complex has also been implicated in telomerase recruitment in human cells (Chai et al. 2006b). Association of the MRN complex at telomeres depends on TRF2 (Zhu et al. 2000). MRE11 and RAD50 are present at human telomeres throughout the cell cycle, whereas NBS1 asso- ciates with telomeres in S phase (Zhu et al. 2000; Loayza and de Lange 2003).

A second telomerase recruitment mechanism in $S$. cerevisiae is provided in G1 through the interaction of the telomere-binding protein $\mathrm{Ku}$ with telomerase (Fisher et al. 2004). Ku recruits telomerase through its specific binding of a stem-loop in TLC1 telomerase RNA (Stellwagen et al. 2003). In the absence of $\mathrm{Ku}$, telomeres are stable, albeit very short, demonstrating that the $\mathrm{Ku}$-mediated recruitment of telomerase is important but not essential for telomerase activity (Boulton and Jackson 1998). Furthermore, the Kumediated recruitment is not sufficient for telomerase recruitment, as evidenced by the dependence of telomereextension on the Cdc13p-Estlp interaction. The $\mathrm{Ku}-$ mediated recruitment of telomerase in G1 may increase the local concentration of telomerase near its substrate, thus favoring the assembly of telomerase with Cdc13p and the telomere $3^{\prime}$ end in S phase. Recently, Piflp helicase overexpression has been demonstrated to remove telomerase from chromosome ends, while its depletion increases telomerase association (Boule et al. 2005). In vitro, Pifl releases telomerase from telomeric oligonucleotide substrates. Pifl also interacts genetically with the Dna2 helicase/nuclease, which is required for Okazaki processing (Budd et al. 2006). It has been proposed that Dna2 and Pif1 may be required for processing of the last Okazaki fragment at the telomere, as there is no pol $\delta / \mathrm{PCNA}$ present to strand displace and to recruit Fen1 (Budd et al. 2006). It will be interesting to determine how Pifl regulates the frequency and extent of telomere elongation in vivo.

In humans, semiconservative DNA replication of telomeres occurs throughout S phase (Ten Hagen et al. 1990; Wright et al. 1999). Direct proof that telomerase action is restricted to this part of the cell cycle is missing. However, based on in situ hybridization studies with oligonucleotide probes, human telomeres are more accessible in $\mathrm{S}$ phase (Jady et al. 2006) and they seem to loose part of their protective structure at the end of $\mathrm{S}$ phase, becoming recognized as DNA damage in G2 (Verdun et al. 2005). The identity of human telomerase recruitment factors is elusive, though human proteins with sequence homology to yeast Estlp have been identified (Reichenbach et al. 2003; Snow et al. 2003). Yeast Est1p and human EST1A and EST1B associate with telomerase in extracts, but their role for telomerase action remains to be elucidated (reviewed by Azzalin et al. 2005).

Recent cytological analyses carried out by two laboratories indicate S-phase-specific assembly of human telomerase with telomeres (Fig. 5) (Jady et al. 2006; Tomlinson et al. 2006). Subcellular localization of endogenous human telomerase RNA was assessed by in situ hybridization, and telomerase reverse transcriptase was detected by indirect immunofluorescence. Human telomerase RNA (hTR) was 

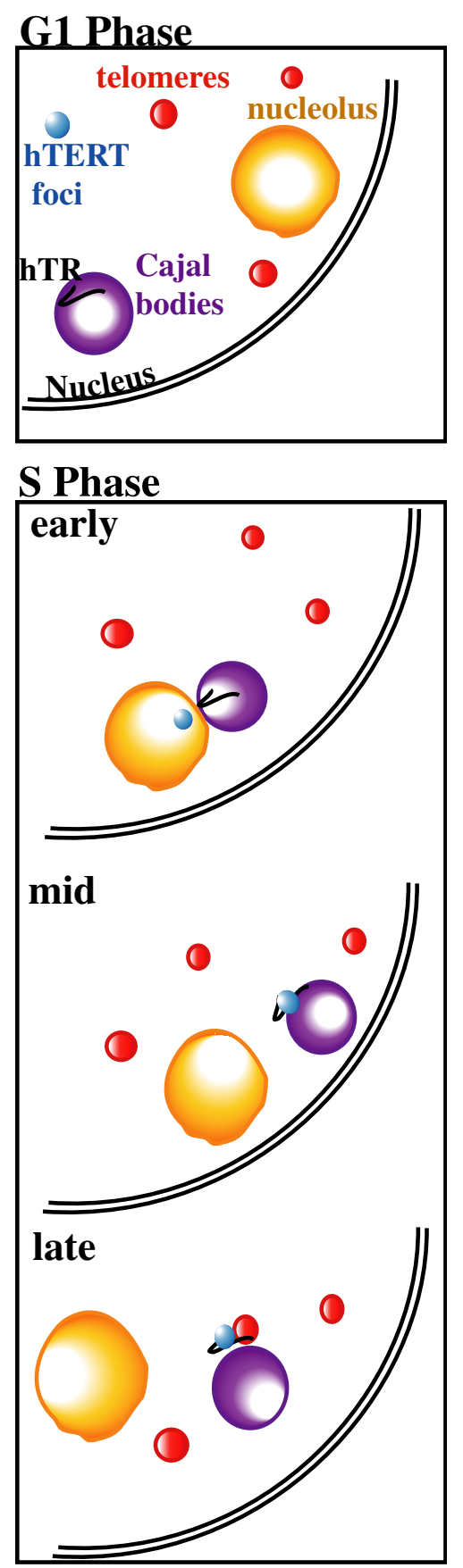

Fig. 5 Cell cycle-dependent assembly of human telomerase and association with telomeres. In G1-cells, hTR is present in Cajal bodies and hTERT is present in nucleoplasmic foci. Early in S phase, Cajal bodies containing hTR are present at the periphery of nucleoli, while hTERT is nucleolar. During S phase, hTERT and hTR are both localized to foci adjacent to Cajal bodies. Some Cajal bodies, hTERT, and hTR are also found in association with telomeres

detected during interphase in Cajal-bodies, dynamic structures involved in the biogenesis of small RNPs. Human TERT (hTERT), on the other hand, was present in nucleoplasmic foci of unknown composition (Tomlinson et al. 2006). Early in S phase, Cajal bodies containing hTR were present at the periphery of nucleoli while hTERT became nucleolar. During S phase, hTERT and hTR both localized to foci adjacent to Cajal bodies. Some Cajal bodies, hTERT and hTR were also found in association with telomeres during $\mathrm{S}$ phase. Live imaging indicated that the association between Cajal bodies and telomeres lasted about $30 \mathrm{~min}$ (Jady et al. 2006). These experiments suggest cell cycle-dependent assembly of active telomerase and cell cycle-dependent association of telomerase with telomeres. Whether hTERT and hTR assemble adjacent to Cajal bodies or at telomeres is not clear yet. The signal intensity of hTERT and hTR at telomeres may suggest that a large number of telomerase molecules associate with single chromosome ends in $\mathrm{S}$ phase. Thus, telomerase may not solely interact with the telomeric $3^{\prime}$ overhangs through base-pairing of the RNA template with telomeric DNA, but recruitment pathways may involve, as in $S$. cerevisiae, interactions with telomeric proteins. Measurements of telomerase in vitro activity did not reveal cell cycledependent changes in the amount of extracted telomerase activity (Holt et al. 1997). It is conceivable that telomerase assembly occurred in extracts upon disruption of subnuclear structures or that a considerable fraction of, perhaps, less focally concentrated but assembled telomerase complexes was not detected in the cytological analyses. The $\mathrm{Rb}$ protein family is required for proper telomere length control in the mouse and it will be interesting to see if and how these cell cycle regulators impinge on telomerase assembly or telomere structure (Garcia-Cao et al. 2002).

\section{Telomere length homeostasis}

The above data indicate that telomerase activity at chromosome ends is only permitted during $\mathrm{S}$ phase. This restriction may be enabled through cell-dependent changes in telomere structure and the cell cycle-restricted assembly of active telomerase. Telomere length homeostasis requires, in addition, mechanisms to measure telomere length in cis, which either promote more efficient elongation of short telomeres by telomerase or which promote activities to shorten preferentially overly long telomeres. Evidence for telomere length regulation in cis became apparent as early as 1982 in experiments in which a linear plasmid containing terminal telomeric repeat seeding sequences from Tetrahymena was transformed and maintained in yeast cells (Szostak and Blackburn 1982). Approximately 200 bp of new yeast telomeric sequence was added de novo to the end of the linear molecule, thus giving a telomere length resembling that of natural yeast chromosomes (Shampay et al. 1984). In yeast, the involvement of the Rap1telomere-binding protein for cis-regulation of telomere length was demonstrated by targeting different numbers of Rap1p carboxyl termini via a heterologous DNA-binding 


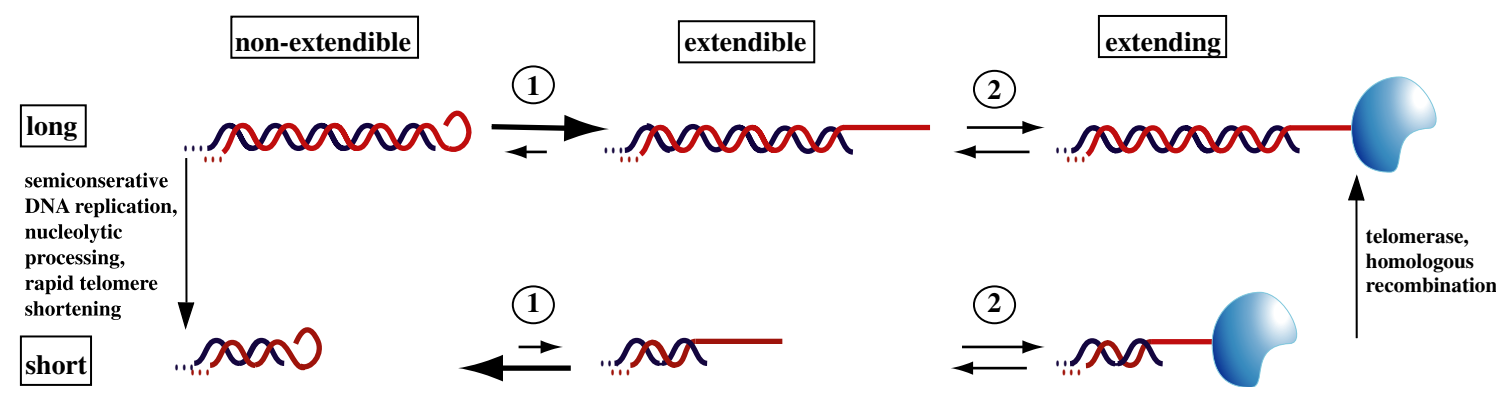

Fig. 6 A three-state model for telomere length homeostasis. Telomeres are proposed to switch between nonextendible (curly end, left), extendible (straight, middle), and extending states (straight end associated with telomerase, right). The equilibrium between non-

domain to a model telomere (Marcand et al. 1997). Telomere length depended on the number of targeted molecules consistent with a feedback mechanism of telomere length regulation. This so-called protein counting mechanism was also recapitulated in human cells with TRF1 and TRF2 (Ancelin et al. 2002).

Observation of the elongation rate of an abnormally shortened telomere in yeast demonstrated length-dependent re-elongation kinetics (Marcand et al. 1999). In mice, crosses between strains with short and long telomeres result in a preferential elongation of short telomeres (Hemann et al. 2001; Samper et al. 2001; Zhu et al. 1998). Similarly, the expression of limiting amounts of telomerase activity in human fibroblasts or in mice leads to preferential elongation of short telomeres (Liu et al. 2002; Ouellette et al. 2000). In the above studies, it was unclear whether the frequency with which telomerase accessed a telomere or the extent of elongation was regulated in a length-dependent manner. A recently developed assay that allows elongation analysis of single telomere molecules in yeast demonstrates that telomerase does not act on every telomere in each cell cycle but that it exhibits an increasing preference for telomeres as their lengths decline (Teixeira et al. 2004). At wild-type length (300 nucleotides), the frequency of telomere elongation was only around $6-8 \%$, while it increased steadily to nearly $50 \%$ upon shortening of telomeres to 100 nucleotides. On the other hand, the number of nucleotides added to a telomere in a single cell cycle varies substantially between a few to more than 100 nucleotides and does not correlate well with telomere length. Thus, the extent of telomere elongation is not regulated in a length-dependent manner. This analysis therefore suggests that telomere length homeostasis is achieved via a switch between telomerase extendible and nonextendible states.

In human cells, it has not yet been demonstrated if the frequency of telomere elongation, the extent of elongation, or both, are regulated in a length-dependent manner. Nevertheless, the current models to explain the cell cycle extendible and extendible states ( 1 ) is a function of telomere length, while the equilibrium between extendible and extending state (2) is a function of telomerase concentration

dependence and the effects of telomere-binding proteins on telomerase activity in vitro invoke the existence of nonextendible states. The t-loop with a telomeric $3^{\prime}$ overhang invading the double-strand telomeric tract should be nonextendible due to the base-paired telomeric $3^{\prime}$ end (Griffith et al. 1999). POT1-bound single-stranded telomeric DNA molecules also inhibit telomerase activity, at least in vitro (Kelleher et al. 2005; Lei et al. 2005).

How is the equilibrium between the putative extendible and nonextendible telomeric states regulated? The nature of these states and the molecular mechanisms of their transition remain speculative. However, it has become apparent that telomerase concentration limits telomere length in mammalian cells and, as argued below, this allows certain conclusions to be drawn about the function and dynamics of telomeric states. In dyskeratosis congenita patients, the decreased expression of telomerase due to mutations in the dyskerin, the telomerase RNA, or the TERT genes causes short telomeres and bone marrow failure (Mitchell et al. 1999; Vulliamy et al. 2001, 2005; Yamaguchi et al. 2005). Haploinsufficiency has also been reported in heterozygous $\mathrm{mTR}^{+/}$and $\mathrm{mTERT}^{+/}$mice (Hathcock et al. 2002; Liu et al. 2002). Interestingly, the length of very short telomeres present in $\mathrm{mTR}^{+-}$mice is not fully reset even in wild-type offspring derived from heterozygous parents, giving rise to a so-called occult form of genetic disease (Hao et al. 2005). On the other hand, an increasing of telomerase activity in human cells over a wide range demonstrates that telomerase association with telomeres as measured by ChIP depends on telomerase concentration (Cristofari and Lingner 2006b). The overexpression of telomerase increased its association with telomeric DNA, and this was sufficient to elongate telomeres in primary or cancer cells in a length-independent manner far beyond physiological size. Thus, even long telomeres are extendible, indicating that they do not permanently adopt a structural nonextendible state. In addition, we predict the existence of a distinct third telomeric state with extendible telomeres switching to an 
extending state, upon productive association with telomerase (Fig. 6). In this model, the transition between the nonextendible and extendible states is length-dependent, whereas the transition between extendible and extending states depends on the concentration of telomerase. Thus, a low cellular concentration of telomerase is critical to achieve preferential elongation of short telomeres and telomere length homeostasis.

The current data suggest that telomerase activity at chromosome ends is regulated by telomere structure and telomerase assembly. Although not proven, the telomere structure may change in a cell cycle-dependent manner to restrict telomerase activity to $\mathrm{S}$ phase. It is conceivable that semiconservative DNA replication through the telomere triggers a structural change that is required to allow telomerase-mediated telomere extension. With limiting concentrations of telomerase, this extension elongates short telomeres more efficiently, but the structural changes at the telomere that mediate this preference are not clear. Perhaps all telomeres are accessible to telomerase for a short period of time after the semiconservative replication of the DNA end, but long telomeres switch back more quickly to a nonextendible state (e.g., a t-loop or $3^{\prime}$ end covered with POT1) than short telomeres, and therefore, short telomeres may have a higher probability to bind telomerase (Fig. 6). PIKKs, telomere-binding proteins, and DNA polymerases involved in lagging strand synthesis may all contribute to this regulation.

\section{Prospects}

Elucidation of the identities of the different cell cycledependent and length-dependent telomeric states remains a difficult challenge. ChIP experiments may contribute to unraveling the molecular composition of telomeres but they do not map the exact binding sites of the crosslinked proteins (Fisher et al. 2004; Takata et al. 2005; Verdun et al. 2005; Zhu et al. 2000). Measuring the fraction of t-loop molecules during the cell cycle may substantiate a putative role of this structure to restrict telomerase activity. The role of PIKKs for telomere maintenance and how they activate telomerase activity is also unclear. The identification of the critical kinase substrates at the telomere or in the telomerase complex and the elucidation of the downstream events of phosphorylation will be an important step. A long-term challenge will be the establishment of in vitro systems in which telomere substrate elongation in vitro recapitulates the in vivo requirements for telomerase recruitment factors, PIKKs, and other factors.

The cell cycle-dependent regulation of telomerase assembly has become apparent recently. The expression of Est1 in yeast is cell cycle-regulated (Taggart et al. 2002), and this restriction may contribute to preventing the unscheduled association of the Est1-Est2-Est3-TLC1 complex with Cdc13p outside of S phase. The mechanisms that regulate cell cycle-dependent assembly of human telomerase and human telomerase's association with telomeres are unexplored. The recent establishment of methods to cytologically detect telomerase components at telomeres will allow the identification of the factors that mediate and regulate these events.

Acknowledgements We focused this review on factors whose functions are well integrated into telomere replication and length homeostasis in S. cerevisiae or human cells. We apologize to those scientists whose work was not mentioned here due to the focus of this review. We thank Gaël Cristofari for Fig. 1. Work in the laboratory was supported by the Swiss National Science Foundation, the Swiss Cancer League, the Human Frontier Science Program, and the EU 6th Framework Programme.

\section{References}

Adams AK, Holm C (1996) Specific DNA replication mutations affect telomere length in Saccharomyces cerevisiae. Mol Cell Biol 16:4614-4620

Ancelin K, Brunori M, Bauwens S, Koering CE, Brun C, Ricoul M, Pommier JP, Sabatier L, Gilson E (2002) Targeting assay to study the cis functions of human telomeric proteins: evidence for inhibition of telomerase by TRF1 and for activation of telomere degradation by TRF2. Mol Cell Biol 22:3474-3487

Armbruster BN, Linardic CM, Veldman T, Bansal NP, Downie DL, Counter CM (2004) Rescue of an hTERT mutant defective in telomere elongation by fusion with hPot1. Mol Cell Biol 24:3552-3561

Azzalin CM, Redon S, Lingner J (2005) S. cerevisiae Est1/H. sapiens SMG6 protein family members function in telomere metabolism. In: Maquat LE (ed) Nonsense-mediated mRNA decay. Landes Bioscience, Georgetown, http://eurekah.com/abstract.php?cha pid $=2781$ \&bookid $=210 \&$ catid $=54$

Baumann P, Cech T (2001) Pot1, the putative telomere end-binding protein in fission yeast and humans. Science 292:1171-1175

Berthiau AS, Yankulov K, Bah A, Revardel E, Luciano P, Wellinger RJ, Geli V, Gilson E (2006) Subtelomeric proteins negatively regulate telomere elongation in budding yeast. EMBO J 25:846-856

Bianchi A, Smith S, Chong L, Elias P, de Lange T (1997) TRF1 is a dimer and bends telomeric DNA. EMBO J 16:1785-1794

Bianchi A, Negrini S, Shore D (2004) Delivery of yeast telomerase to a DNA break depends on the recruitment functions of Cdc13 and Est1. Mol Cell 16:139-146

Boule JB, Vega LR, Zakian VA (2005) The yeast Piflp helicase removes telomerase from telomeric DNA. Nature 438:57-61

Boulton SJ, Jackson SP (1998) Components of the Ku-dependent nonhomologous end-joining pathway are involved in telomeric length maintenance and telomeric silencing. EMBO J 17:1819-1828

Bourns BD, Alexander MK, Smith AM, Zakian VA (1998) Sir proteins, Rif proteins, and $\mathrm{Cdc} 13 \mathrm{p}$ bind Saccharromyces telomers in vivo. Mol Cell Biol 18:5600-5608

Budd ME, Reis CC, Smith S, Myung K, Campbell JL (2006) Evidence suggesting that Pifl helicase functions in DNA replication with the Dna2 helicase/nuclease and DNA polymerase delta. Mol Cell Biol 26:2490-2500 
Chai W, Du Q, Shay JW, Wright WE (2006a) Human telomeres have different overhang sizes at leading versus lagging strands. Mol Cell 21:427-435

Chai W, Sfeir AJ, Hoshiyama H, Shay JW, Wright WE (2006b) The involvement of the Mre11/Rad50/Nbs1 complex in the generation of G-overhangs at human telomeres. EMBO Rep 7:225-230

Chandra A, Hughes TR, Nugent CI, Lundblad V (2001) Cdc13 both positively and negatively regulates telomere replication. Genes Dev 15:404-414

Chang W, Dynek JN, Smith S (2003) TRF1 is degraded by ubiquitinmediated proteolysis after release from telomeres. Genes Dev 17:1328-1333

Chen J-L, Greider CW (2006) Telomerase biochemistry and biogenesis. In: de Lange T, Lundblad V, Blackburn EH (eds) Telomeres. Cold Spring Harbor Laboratory Press, Cold Spring Harbor, pp 49-79

Chen JL, Blasco MA, Greider CW (2000) Secondary structure of vertebrate telomerase RNA. Cell 100:503-514

Colgin LM, Baran K, Baumann P, Cech TR, Reddel RR (2003) Human POT1 facilitates telomere elongation by telomerase. Curr Biol 13:942-946

Conrad M, Wright J, Wolf J, Zakian V (1990) RAP1 protein interacts with yeast telomeres in vivo: overproduction alters telomere structure and decreases chromosome stability. Cell 63:739-750

Cook BD, Dynek JN, Chang W, Shostak G, Smith S (2002) Role for the related poly(ADP-Ribose) polymerases tankyrase 1 and 2 at human telomeres. Mol Cell Biol 22:332-342

Cristofari G, Lingner J (2006a) The telomerase ribonucleoprotein particle. In: de Lange $\mathrm{T}$, Lundblad V, Blackburn EH (ed) Telomeres. Cold Spring Harbor Laboratory Press, Cold Spring Harbor, pp 21-47

Cristofari G, Lingner J (2006b) Telomere length homeostasis requires that telomerase levels are limiting. EMBO J 25:565-574

Dandjinou AT, Levesque N, Larose S, Lucier JF, Elela SA, Wellinger RJ (2004) A phylogenetically based secondary structure for the yeast telomerase RNA. Curr Biol 14:1148-1158

de Lange T (2005) Shelterin: the protein complex that shapes and safeguards human telomeres. Genes Dev 19:2100-2110

Diede SJ, Gottschling DE (1999) Telomerase-mediated telomere addition in vivo requires DNA primase and DNA polymerases alpha and delta. Cell 99:723-733

Evans SK, Lundblad V (1999) Est1 and Cdc13 as comediators of telomerase access. Science 286:117-120

Fisher TS, Taggart AK, Zakian VA (2004) Cell cycle-dependent regulation of yeast telomerase by $\mathrm{Ku}$. Nat Struct Mol Biol 11:1198-1205

Garcia-Cao M, Gonzalo S, Dean D, Blasco MA (2002) A role for the $\mathrm{Rb}$ family of proteins in controlling telomere length. Nat Genet 32:415-419

Garcia-Cao M, O'Sullivan R, Peters AH, Jenuwein T, Blasco MA (2004) Epigenetic regulation of telomere length in mammalian cells by the Suv39h1 and Suv39h2 histone methyltransferases. Nat Genet 36:94-99

Garvik B, Carson M, Hartwell L (1995) Single-stranded DNA arising at telomeres in cdc13 mutants may constitute a specific signal for the RAD9 checkpoint. Mol Cell Biol 15:6128-6138

Grandin N, Reed SI, Charbonneau M (1997) Stn1, a new Saccharomyces cerevisiae protein, is implicated in telomere size regulation in association with Cdc13. Genes Dev 11:512-527

Grandin N, Damon C, Charbonneau M (2001) Ten1 functions in telomere end protection and length regulation in association with Stn1 and Cdc13. EMBO J 20:1173-1183

Greider CW, Blackburn EH (1985) Identification of a specific telomere terminal transferase activity in Tetrahymena extracts. Cell 43:405-413
Greider CW, Blackburn EH (1987) The telomere terminal transferase of Tetrahymena is a ribonucleoprotein enzyme with two kinds of primer specificity. Cell 51:887-898

Greider CW, Blackburn EH (1989) A telomeric sequence in the RNA of Tetrahymena telomerase required for telomere repeat synthesis. Nature 337:331-337

Griffith JD, Comeau L, Rosenfield S, Stansel RM, Bianchi A, Moss $\mathrm{H}$, de Lange $\mathrm{T}$ (1999) Mammalian telomeres end in a large duplex loop. Cell 97:503-514

Grossi S, Puglisi A, Dmitriev PV, Lopes M, Shore D (2004) Pol12, the B subunit of DNA polymerase alpha, functions in both telomere capping and length regulation. Genes Dev 18:992-1006

Hao LY, Armanios M, Strong MA, Karim B, Feldser DM, Huso D, Greider CW (2005) Short telomeres, even in the presence of telomerase, limit tissue renewal capacity. Cell 123:1121-1131

Hardy CF, Sussel L, Shore D (1992) A RAP1-interacting protein involved in transcriptional silencing and telomere length regulation. Genes Dev 6:801-814

Hathcock KS, Hemann MT, Opperman KK, Strong MA, Greider CW, Hodes RJ (2002) Haploinsufficiency of mTR results in defects in telomere elongation. Proc Natl Acad Sci USA 99:3591-3596

Hemann MT, Strong MA, Hao LY, Greider CW (2001) The shortest telomere, not average telomere length, is critical for cell viability and chromosome stability. Cell 107:67-77

Holt SE, Aisner DL, Shay JW, Wright WE (1997) Lack of cell cycle regulation of telomerase activity in human cells. Proc Natl Acad Sci USA 94:10687-10692

Houghtaling BR, Cuttonaro L, Chang W, Smith S (2004) A dynamic molecular link between the telomere length regulator TRF1 and the chromosome end protector TRF2. Curr Biol 14:1621-1631

Jacob NK, Kirk KE, Price CM (2003) Generation of telomeric G strand overhangs involves both $\mathrm{G}$ and $\mathrm{C}$ strand cleavage. Mol Cell 11:1021-1032

Jady BE, Richard P, Bertrand E, Kiss T (2006) Cell cycle-dependent recruitment of telomerase RNA and Cajal bodies to human telomeres. Mol Biol Cell 17:944-954

Kaminker PG, Kim SH, Taylor RD, Zebarjadian Y, Funk WD, Morin GB, Yaswen P, Campisi J (2001) TANK2, a new TRF1-associated poly(ADP-ribose) polymerase, causes rapid induction of cell death upon overexpression. J Biol Chem 276:35891-35899

Kelleher C, Kurth I, Lingner J (2005) Human protection of telomeres 1 (POT1) is a negative regulator of telomerase activity in vitro. Mol Cell Biol 25:808-818

Kim SH, Beausejour C, Davalos AR, Kaminker P, Heo SJ, Campisi J (2004) TIN2 mediates functions of TRF2 at human telomeres. J Biol Chem 279:43799-43804

Kim SH, Kaminker P, Campisi J (1999) TIN2, a new regulator of telomere length in human cells. Nat Genet 23:405-412

Klobutcher LA, Swanton MT, Donini P, Prescott DM (1981) All genesized DNA molecules in four species of hypotrichs have the same terminal sequence and an unusual $3^{\prime}$ terminus. Proc Natl Acad Sci USA 78:3015-3019

Larrivee M, LeBel C, Wellinger RJ (2004) The generation of proper constitutive G-tails on yeast telomeres is dependent on the MRX complex. Genes Dev 18:1391-1396

Lei M, Podell ER, Cech TR (2004) Structure of human POT1 bound to telomeric single-stranded DNA provides a model for chromosome end-protection. Nat Struct Mol Biol 11:1223-1229

Lei M, Zaug AJ, Podell ER, Cech TR (2005) Switching human telomerase on and off with hPOT1 protein in vitro. J Biol Chem 280:20449-20456

Lendvay TS, Morris DK, Sah J, Balasubramanian B, Lundblad V (1996) Senescence mutants of Saccharomyces cerevisiae with a defect in telomere replication identify three additional EST genes. Genetics 144:1399-1412 
Li B, de Lange T (2003) Rap1 affects the length and heterogeneity of human telomeres. Mol Biol Cell 14:5060-5068

Li B, Oestreich S, de Lange T (2000) Identification of human Rap1: implications for telomere evolution. Cell 101:471-483

Lingner J, Promisel Cooper J, Cech TR (1995) Telomerase and DNA end replication: no longer a lagging strand problem? Science 269:1533-1534

Lingner J, Hughes TR, Shevchenko A, Mann M, Lundblad V, Cech TR (1997) Reverse transcriptase motifs in the catalytic subunit of telomerase. Science 276:561-567

Liu D, O'Connor MS, Qin J, Songyang Z (2004a) Telosome, a mammalian telomere-associated complex formed by multiple telomeric proteins. J Biol Chem 279:51338-51342

Liu D, Safari A, O’Connor MS, Chan DW, Laegeler A, Qin J, Songyang Z (2004b) PTOP interacts with POT1 and regulates its localization to telomeres. Nat Cell Biol 6:673-680

Liu Y, Kha H, Ungrin M, Robinson MO, Harrington L (2002) Preferential maintenance of critically short telomeres in mammalian cells heterozygous for mTert. Proc Natl Acad Sci USA 99:3597-3602

Loayza D, De Lange T (2003) POT1 as a terminal transducer of TRF1 telomere length control. Nature 424:1013-1018

Lundblad V, Szostak JW (1989) A mutant with a defect in telomere elongation leads to senescence in yeast. Cell 57:633-643

Lustig A, Kurtz S, Shore D (1990) Involvement of the silencer and UAS binding protein Rap1 in regulation of telomere length. Science 250:549-553

Makarov VL, Hirose Y, Langmore JP (1997) Long G tails at both ends of human chromosomes suggest a $\mathrm{C}$ strand degradation mechanism for telomere shortening. Cell 88:657-666

Marcand S, Gilson E, Shore D (1997) A protein-counting mechanism for telomere length regulation in yeast. Science 275:986-990

Marcand S, Brevet V, Gilson E (1999) Progressive cis-inhibition of telomerase upon telomere elongation. EMBO J 18:3509-3519

Marcand S, Brevet V, Mann C, Gilson E (2000) Cell cycle restriction of telomere elongation. Curr Biol 10:487-490

Mitchell JR, Wood E, Collins K (1999) A telomerase component is defective in the human disease dyskeratosis congenita. Nature 402:551-555

Naito T, Matsuura A, Ishikawa F (1998) Circular chromosome formation in a fission yeast mutant defective in two atm homologues. Nat Genet 20:203-206

Nakamura M, Nabetani A, Mizuno T, Hanaoka F, Ishikawa F (2005) Alterations of DNA and chromatin structures at telomeres and genetic instability in mouse cells defective in DNA polymerase alpha. Mol Cell Biol 25:11073-11088

Nugent CI, Hughes TR, Lue NF, Lundblad V (1996) Cdc13p: a single-strand telomeric DNA-binding protein with a dual role in yeast telomere maintenance. Science 274:249-252

O'Connor MS, Safari A, Liu D, Qin J, Songyang Z (2004) The human Rap1 protein complex and modulation of telomere length. J Biol Chem 279:28585-28591

Olovnikoff AM (1973) A theory of marginotomy. The incomplete copying of template margins in enzymic synthesis of polynucleotides and biological significance of the phenomenon. J Theor Biol 41:181-190

Opresko PL, Mason PA, Podell ER, Lei M, Hickson ID, Cech TR, Bohr VA (2005) POT1 stimulates RecQ helicases WRN and BLM to unwind telomeric DNA substrates. J Biol Chem 280:32069-32080

Ouellette MM, Liao M, Herbert BS, Johnson M, Holt SE, Liss HS, Shay JW, Wright WE (2000) Subsenescent telomere lengths in fibroblasts immortalized by limiting amounts of telomerase. J Biol Chem 275:10072-10076

Pennock E, Buckley K, Lundblad V (2001) Cdc13 delivers separate complexes to the telomere for end protection and replication. Cell 104:387-396
Qi H, Zakian VA (2000) The Saccharomyces telomere-binding protein Cdc13p interacts with both the catalytic subunit of DNA polymerase alpha and the telomerase-associated Est1 protein. Genes Dev 14:1777-1788

Reichenbach P, Hoss M, Azzalin CM, Nabholz M, Bucher P, Lingner J (2003) A human homolog of yeast Estl associates with telomerase and uncaps chromosome ends when overexpressed. Curr Biol 13:568-574

Ritchie KB, Mallory JC, Petes TD (1999) Interactions of TLC1 (which encodes the RNA subunit of telomerase), TEL1, and MEC1 in regulating telomere length in the yeast Saccharomyces cerevisiae. Mol Cell Biol 19:6065-6075

Samper E, Flores JM, Blasco MA (2001) Restoration of telomerase activity rescues chromosomal instability and premature aging in Terc-/- mice with short telomeres. EMBO Rep 2:800-807

Sbodio JI, Lodish HF, Chi NW (2002) Tankyrase-2 oligomerizes with tankyrase-1 and binds to both TRF1 (telomere-repeat-binding factor 1) and IRAP (insulin-responsive aminopeptidase). Biochem J 361:451-459

Schramke V, Luciano P, Brevet V, Guillot S, Corda Y, Longhese MP, Gilson E, Geli V (2004) RPA regulates telomerase action by providing Est1p access to chromosome ends. Nat Genet $36: 46-54$

Seimiya H, Smith S (2002) The telomeric poly(ADP-ribose) polymerase, tankyrase 1, contains multiple binding sites for telomeric repeat binding factor 1 (TRF1) and a novel acceptor, 182-kDa tankyrase-binding protein (TAB182). J Biol Chem 277:14116-14126

Seto AG, Zaug AJ, Sobel SG, Wolin SL, Cech TR (1999) Saccharomyces cerevisiae telomerase is an Sm small nuclear ribonucleoprotein particle. Nature 401:177-180

Sfeir AJ, Chai W, Shay JW, Wright WE (2005) Telomere-end processing the terminal nucleotides of human chromosomes. Mol Cell 18:131-138

Shampay J, Szostak J, Blackburn E (1984) DNA sequences of telomeres maintained in yeast. Nature 310:154-157

Smith S, de Lange T (2000) Tankyrase promotes telomere elongation in human cells. Curr Biol 10:1299-1302

Smith S, Giriat I, Schmitt A, de Lange T (1998) Tankyrase, a poly (ADP-ribose) polymerase at human telomeres. Science 282:1484-1487

Smogorzewska A, De Lange T (2004) Regulation of telomerase by telomeric proteins. Annu Rev Biochem 73:177-208

Smogorzewska A, van Steensel B, Bianchi A, Oelmann S, Schaefer MR, Schnapp G, de Lange T (2000) Control of human telomere length by TRF1 and TRF2. Mol Cell Biol 20:1659-1668

Snow BE, Erdmann N, Cruickshank J, Goldman H, Gill RM, Robinson MO, Harrington L (2003) Functional conservation of the telomerase protein Est1p in humans. Curr Biol 13:698-704

Stellwagen AE, Haimberger ZW, Veatch JR, Gottschling DE (2003) Ku interacts with telomerase RNA to promote telomere addition at native and broken chromosome ends. Genes Dev 17:2384-2395

Szostak J, Blackburn E (1982) Cloning yeast telomeres on linear plasmid vectors. Cell 29:245-255

Taggart AK, Teng SC, Zakian VA (2002) Estlp as a cell cycle-regulated activator of telomere-bound telomerase. Science 297:1023-1026

Takata H, Kanoh Y, Gunge N, Shirahige K, Matsuura A (2004) Reciprocal association of the budding yeast ATM-related proteins Tel1 and Mec1 with telomeres in vivo. Mol Cell 14:515-522

Takata H, Tanaka Y, Matsuura A (2005) Late S phase-specific recruitment of Mre11 complex triggers hierarchical assembly of telomere replication proteins in Saccharomyces cerevisiae. Mol Cell 17:573-583

Teixeira MT, Arneric M, Sperisen P, Lingner J (2004) Telomere length homeostasis is achieved via a switch between telomeraseextendible and -nonextendible states. Cell 117:323-335 
Ten Hagen KG, Gilbert DM, Willard HF, Cohen SN (1990) Replication timing of DNA sequences associated with human centromeres and telomeres. Mol Cell Biol 10:6348-6355

Tomlinson RL, Ziegler TD, Supakorndej T, Terns RM, Terns MP (2006) Cell cycle-regulated trafficking of human telomerase to telomeres. Mol Biol Cell 17:955-965

van Steensel B, de Lange T (1997) Control of telomere length by the human telomeric protein TRF1. Nature 385:740-743

Verdun RE, Crabbe L, Haggblom C, Karlseder J (2005) Functional human telomeres are recognized as DNA damage in G2 of the cell cycle. Mol Cell 20:551-561

Vulliamy T, Marrone A, Goldman F, Dearlove A, Bessler M, Mason PJ, Dokal I (2001) The RNA component of telomerase is mutated in autosomal dominant dyskeratosis congenita. Nature 413:432-435

Vulliamy TJ, Walne A, Baskaradas A, Mason PJ, Marrone A, Dokal I (2005) Mutations in the reverse transcriptase component of telomerase (TERT) in patients with bone marrow failure. Blood Cells Mol Dis 34:257-263

Watson J (1972) Origin of concatemeric T7 DNA. Nat New Biol 239:197-201

Wellinger RJ, Wolf AJ, Zakian VA (1993) Saccharomyces telomeres acquire single-strand TG1-3 tails late in S phase. Cell 72:51-60

Wotton D, Shore D (1997) Novel Rap1p-interacting factor, Rif2p, cooperates with Riflp to regulate telomere length in Saccharomyces cerevisiae. Genes Dev 11:748-760

Wright WE, Tesmer VM, Liao ML, Shay JW (1999) Normal human telomeres are not late replicating. Exp Cell Res 251:492-499

Yamaguchi H, Calado RT, Ly H, Kajigaya S, Baerlocher GM, Chanock SJ, Lansdorp PM, Young NS (2005) Mutations in TERT, the gene for telomerase reverse transcriptase, in aplastic anemia. N Engl J Med 352:1413-1424
Yang Q, Zheng YL, Harris CC (2005) POT1 and TRF2 cooperate to maintain telomeric integrity. Mol Cell Biol 25:1070-1080

Ye JZ, de Lange T (2004) TIN2 is a tankyrase 1 PARP modulator in the TRF1 telomere length control complex. Nat Genet 36:618-623

Ye JZ, Donigian JR, van Overbeek M, Loayza D, Luo Y, Krutchinsky AN, Chait BT, de Lange T (2004a) TIN2 binds TRF1 and TRF2 simultaneously and stabilizes the TRF2 complex on telomeres. J Biol Chem 279:47264-47271

Ye JZ, Hockemeyer D, Krutchinsky AN, Loayza D, Hooper SM, Chait BT, de Lange T (2004b) POT1-interacting protein PIP1: a telomere length regulator that recruits POT1 to the TIN2/TRF1 complex. Genes Dev 18:1649-1654

Yu GL, Bradley JD, Attardi LD, Blackburn EH (1990) In vivo alteration of telomere sequences and senescence caused by mutated Tetrahymena telomerase RNAs. Nature 344:126-132

Zahler AM, Williamson JR, Cech TR, Prescott DM (1991) Inhibition of telomerase by G-quartet DNA structures. Nature 350:718-720

Zappulla DC, Cech TR (2004) Yeast telomerase RNA: a flexible scaffold for protein subunits. Proc Natl Acad Sci USA 101:10024-10029

Zaug AJ, Podell ER, Cech TR (2005) Human POT1 disrupts telomeric G-quadruplexes allowing telomerase extension in vitro. Proc Natl Acad Sci USA 102:10864-10869

Zhu LX, Hathcock KS, Hande P, Lansdorp PM, Seldin MF, Hodes RJ (1998) Telomere length regulation in mice is linked to a novel chromosome locus. Proc Natl Acad Sci USA 95:8648-8653

Zhu XD, Kuster B, Mann M, Petrini JH, Lange T (2000) Cell-cycleregulated association of RAD50/MRE11/NBS1 with TRF2 and human telomeres. Nat Genet 25:347-352 